\title{
Microstructural evolution and mechanical properties of in situ nano Ta4HfC5 reinforced SiBCN composite ceramics
}

\section{Bingzhu Wang}

Harbin Institute of Technology

Li Daxin ( $\nabla$ lidaxin@hit.edu.cn )

Harbin Institute of Technology https://orcid.org/0000-0003-4930-0031

Zhihua Yang

Harbin Institute of Technology

Dechang Jia

Harbin Institute of Technology

Jingyi Guan

Harbin Institute of Technology

Hao Peng

Harbin Institute of Technology

Delong Cai

Harbin Institute of Technology

Peigang He

Harbin Institute of Technology

Xiaoming Duan

Harbin Institute of Technology

Yu Zhou

Harbin Institute of Technology

\section{Research Article}

Keywords: Ta4HfC5; SiBCN; Microstructure evolution; Mechanical properties

Posted Date: March 18th, 2020

DOI: https://doi.org/10.21203/rs.3.rs-17623/v1

License: (c) (1) This work is licensed under a Creative Commons Attribution 4.0 International License.

Read Full License 
Version of Record: A version of this preprint was published at Journal of Advanced Ceramics on November 27th, 2020. See the published version at https://doi.org/10.1007/s40145-020-0410-9. 


\section{Abstract}

In this paper, the in situ nano Ta $4 \mathrm{HfC} 5$ reinforced SiBCN-Ta $4 \mathrm{HfC} 5$ composite ceramics were prepared by a combination of two-step mechanical alloying and reactive hot-pressing sintering. The microstructural evolution and mechanical properties of the SiBCN-Ha $4 \mathrm{HfC} 5$ were studied. After the firststep milling of $30 \mathrm{~h}$, the raw materials of $\mathrm{TaC}$ and $\mathrm{HfC}$ undergone crushing, cold sintering and short-range interdiffusion to finally obtain the high pure nano Ta $4 \mathrm{HfC} 5$. A hybrid structure of amorphous SiBCN and nano Ta $4 \mathrm{HfC} 5$ was obtained by adopting a second-step ball-milling. After reactive hot-pressing sintering, amorphous $\mathrm{SiBCN}$ has crystallized to nano $\mathrm{SiC}$ and turbostratic $\mathrm{BN}(\mathrm{C})$ phases while $\mathrm{Ta} 4 \mathrm{HfC} 5$ retained the form of nano structure. With the in situ generation of $2.5 \mathrm{wt} \% \mathrm{Ta} 4 \mathrm{HfC} 5, \mathrm{Ta} 4 \mathrm{HfC} 5$ is preferentially distributed within the turbostratic $\mathrm{BN}(\mathrm{C})$; however, as Ta $4 \mathrm{HfC} 5$ content further raised to 10 $w t \%$, it mainly distributed in the grain-boundary of $\mathrm{BN}(\mathrm{C})$ and SiC. The introduction of Ta $4 \mathrm{HfC} 5$ nanocrystals can effectively improve the flexural strength and fracture toughness of SiBCN ceramics, reaching to $344.1 \mathrm{MPa}$ and $4.52 \mathrm{MPa} \cdot \mathrm{m} 1 / 2$, respectively.

\section{Introduction}

With the development of aerospace technology, more stringent properties requirements are put forward for advanced structural-functional integration ceramic materials ${ }^{[1]}$. Among many high-temperature structural materials, SiBCN non-oxide ceramics have attracted considerable attention due to their lightweight, high specific strength, excellent thermal stability and resistance to thermal shock, oxidation and ablation ${ }^{[2-7]}$.

Polymer/precursor derived ceramics (PDCs) is one of the first routes to prepare SiBCN materials. The $\mathrm{SiBCN}$ materials are able to remain amorphous nature at least up to $1400{ }^{\circ} \mathrm{C}$, and do not undergo microstructural changes at this temperature ${ }^{[4]}$. The chemistry, microstructure and properties of the PDCs SiBCN can be tailored effectively by controlling the initial reagent structure, chemical reaction and processing parameters ${ }^{[8]}$. Unfortunately, this method also has some nonnegligible shortcomings that limit its wide applications. The starting materials are usually expensive and some organic solvents used are harmful to human health and the environment. This processing route is also low-yield and complex. During pyrolysis, the gases release and the mass loss are required to be carefully monitored to avoid porous structure and accurately control shrinkage (even microcracks) ${ }^{[9-11]}$.

Thus, a more efficient, convenient and environment-friendly method was proposed to obtain dense nano or amorphous $\mathrm{SiBCN}$ monoliths and their ceramic composites, using a combination of mechanical alloying and solid-state sintering techniques (also referred as inorganic method) ${ }^{[10]}$. One of the significant advantages of this processing route is to provide centimeter-sized samples. The centimetersized samples are convenient for evaluating the basic mechanical and thermophysical properties ${ }^{[11-12]}$. However, the previous studies showed that the heterogeneous microstructure, which leads to poor 
mechanical properties of the SiBCN ceramics, are needed to be further optimized for the real applications at high-temperatures ${ }^{[13-14]}$.

As documented, the introduction of ultra-high temperature ceramics (UHTCs) into SiBCN ceramic matrix, is considered to be an effective strategy to improve the mechanical performance of SiBCN ceramics ${ }^{[15-}$ ${ }^{18]}$. In previous attempts, the microstructural evolution and thermal stability of the porous PDCs $\mathrm{ZrB}_{2}{ }^{-}$ $\mathrm{SiBCN}$ and $\mathrm{HfN}-\mathrm{SiBCN}$ composite ceramics have been investigated ${ }^{[19-20]}$. But the mechanical properties of these composite ceramics have not been evaluated because of the limitation of sample size. In another contribution, Liang et al. ${ }^{[21-23]}$ have introduced some $\mathrm{LaB}_{6}$ into $\mathrm{SiBCN}$ matrix by the inorganic method, obtaining desirable mechanical properties compared with pure SiBCN. However, during the sintering process, some $L_{a B} B_{6}$ has reacted with $S i B C N$ ceramic matrix and generated $L_{2} B_{2} C_{6}$. Consequently, the strengthening and toughening effects of $\mathrm{LaB}_{6}$ were significantly reduced. Further, Miao et al. ${ }^{[24-26]}$ have prepared $\mathrm{SiBCN}-\mathrm{ZrB}_{2}$ composite ceramics by mechanical alloying combined with the sol-gel method. The results suggested that the in situ $\mathrm{ZrB}_{2}$ can improve the mechanical properties of $\mathrm{SiBCN}$ ceramic materials to some extent; nevertheless, the particle size of the in-situ $\mathrm{ZrB}_{2}$ has grown up to a maximum value of $\sim 1 \mu \mathrm{m}$.

Generally, the following factors should be considered when the external UHTCs are selected as reinforcements in SiBCN ceramics: (i) they should not react with SiBCN matrix to form strong bonding interfacial structure during annealing or sintering; (ii) they could be uniformly dispersed in ceramic matrix in the form of nanocrystals and (iii) are supposed to have good physical-chemical compatibility with SiBCN.

The chemically stable $\mathrm{Ta}_{4} \mathrm{HfC}_{5}$, the current highest melting point compound, was theoretically forecasted by Agte et al. ${ }^{[27]}$ and experimentlly confirmed by Andrievskii et al. ${ }^{[28]}$ Up to present, various strategies have been used to the synthesis of the high pure $\mathrm{Ta}_{4} \mathrm{HfC}_{5}$. For example, Simonenko et al. ${ }^{[29]}$ have reported a sol-gel technology for preparing $\mathrm{Ta}_{4} \mathrm{HfC}_{5}$ by using metal oxide and gel of polymeric carbon source. The polymeric carbon source was preliminarily annealing to provide a uniform dispersion of metal oxide-carbon mixture, and then further heating to $1200 \sim 1500{ }^{\circ} \mathrm{C}$ to obtain pure $\mathrm{Ta}_{4} \mathrm{HfC}_{5}$. Liu et al. ${ }^{[30]}$ used the $\mathrm{Hf}$ and Ta containing polytantahafnoxane modified with allyl-functional novolac resin to produce $\mathrm{Ta}_{4} \mathrm{HfC}_{5}$ polymer (polytantahafnoxanesal). The resulting polytantahafnoxanesal is subsequently solidified and pyrolyzed at $1400^{\circ} \mathrm{C}$ to obtain pure $\mathrm{Ta}_{4} \mathrm{HfC}_{5}$. These methods, of course, are quite effective to prepare pure $\mathrm{Ta}_{4} \mathrm{HfC}_{5}$ with high thermal stability and chemical stability; however, these processing methods often contain complex synthesis steps, resulting in high-cost products. The raw materials used are also flammable and present waste disposal problems. For this reason, Osama et al. ${ }^{\left[{ }^{31]}\right.}$ have successfully prepared nano $\mathrm{Ta}_{4} \mathrm{HfC}_{5}$ by mechanical alloying for the first time. However, the formation mechanisms of the mechanical alloying derived nano $\mathrm{Ta}_{4} \mathrm{HfC}_{5}$ is still unclear. And the research on $\mathrm{Ta}_{4} \mathrm{HfC}_{5} / \mathrm{SiBCN}$ composite ceramics has not been reported yet. 
Thus, in this work, initially, the $\mathrm{Ta}_{4} \mathrm{HfC}_{5}$ nanocrystals were prepared by an improving mechanical alloying method and then, nano $\mathrm{Ta}_{4} \mathrm{HfC}_{5}$ was introduced to the prefabricated amorphous SiBCN powders by a second stage of mechanical alloying. Afterward, the hot-pressing sintering technology was adopted to consolidate $\mathrm{SiBCN}-\mathrm{Ta}_{4} \mathrm{HfC}_{5}$ composite ceramics. The formation mechanisms of mechanical alloying derived nano $\mathrm{Ta}_{4} \mathrm{HfC}_{5}$, the correlation of microstructural evolution and mechanical properties of the resulting $\mathrm{SiBCN}-\mathrm{Ta}_{4} \mathrm{HfC}_{5}$ composite ceramics were illustrated. As expected, the homogeneous distribution of nano $\mathrm{Ta}_{4} \mathrm{HfC}_{5}$ within the $\mathrm{SiBCN}$ ceramic matrix strongly improved the mechanical properties of the composite ceramics. This work has solved the problems of uneven distribution of ultra-high temperature phases in the ceramic matrix, which is beneficial to the real applications of SiBCN ceramics.

\section{Materials And Methods}

\section{Raw materials}

Commercial available hexagonal boron nitride (h-BN, 99.0\% purity, $0.6 \mu \mathrm{m}$, purchased from Advanced Technology \&Materials Co., Ltd), graphite (99.5\% purity, $8.7 \mu \mathrm{m}$, purchased from Qingdao Huatai Lubricant Sealing S\&T Co., Ltd), cubic silicon (c-Si, 99.9\% purity, $9.0 \mu \mathrm{m}$, purchased from China New Metal Materials Technology Co., Ltd.), hafnium carbide (HfC, 99.0\% purity, $1 \mu \mathrm{m}$, purchased from Shanghai Puwei Applied Materials Technology Co., Ltd) and tantalum carbide (TaC, 99.0\% purity, $1 \mu \mathrm{m}$, purchased from Shanghai Puwei Applied Materials Technology Co., Ltd) were used here as received.

\section{Synthesis of $\mathrm{Ta}_{4} \mathrm{HfC}_{5}$ nanocrystals}

$\mathrm{Ta}_{4} \mathrm{HfC}_{5}$ nanocrystals were prepared by mechanical alloying method via a $\mathrm{P} 4$ high-energy ball-miller manufactured by FRITSCH company. Firstly, TaC and HfC mixed powders with a molar ratio of 4: 1 were poured into the ball milling tanks filled with argon, and then subjected to different hours of milling. The ball-to-powder mass ratio was set as 20: 1 and the effective ball-milling time was $\mathrm{X} h(\mathrm{X}=0.5,1,1.5,2,3$, $5,10,20,30 \mathrm{~h}$ ). The main disc was rotated at $350 \mathrm{rpm}$ while the vials were rotated at $800 \mathrm{rpm}$ in reverse.

\section{Synthesis of $\mathrm{SiBCN}-\mathrm{Ta}_{4} \mathrm{HfC}_{5}$ powder and bulk ceramics}

In this stage, c-Si, h-BN, graphite with a molar ratio of $=2: 1: 3$, and $2.5 \mathrm{wt} \%, 5 \mathrm{wt} \%, 10 \mathrm{wt} \% \mathrm{Ta}_{4} \mathrm{HfC}_{5}$ nanocrystals were put into ball milling tanks. Before the milling process, the rotation speed of the main disc was set at $350 \mathrm{rpm}$ while the vials were rotated at $600 \mathrm{rpm}$ in reverse. In this scene, the effective milling time of $20 \mathrm{~h}$ could ensure a well-defined microstructure of the mixtures ${ }^{[32-33]}$. The steps of mixing, storage and transportation are performed in high purity Ar.

$\mathrm{SiBCN}-\mathrm{Ta}_{4} \mathrm{HfC}_{5}$ mixed powders were loaded into a graphite mould with a diameter of $36 \mathrm{~mm}$, and then sintered via the hot-pressing sintering system (50-250T model, AVS company, USA). The sintering was conducted at a temperature of $1900^{\circ} \mathrm{C}$ and holding time for $1 \mathrm{~h}$ under an axial pressure of $60 \mathrm{MPa}$. The 
content of $\mathrm{Ta}_{4} \mathrm{HfC}_{5}$ in SiBCN-Ta $\mathrm{HfC}_{5}$ composite ceramics is 0 wt\%, 2.5 wt\%, 5 wt\%, 10 wt\% and 15 wt\%, respectively.

\section{Characterization}

The phase composition of the samples was measured by X'PERT X-ray diffractometer purchased from Panalytical Company of Netherlands. The scanning speed is $10^{\circ} / \mathrm{min}$ and the scanning range is $10^{\circ}-90^{\circ}$. The morphologies of the samples were observed by using NanoLab 600i scanning electron microscope produced by FEl company. Tecnal $\mathrm{G}^{2} \mathrm{~F} 20$ transmission electron microscope from FEl company was used to observe the microstructure of $\mathrm{Ta}_{4} \mathrm{HfC}_{5}$ and $\mathrm{SiBCN}-\mathrm{Ta}_{4} \mathrm{HfC}_{5}$ powders. The microstructure and element distribution of the $\mathrm{SiBCN}-\mathrm{Ta}_{4} \mathrm{HfC}_{5}$ composite ceramics were investigated by using Talos f200x transmission electron microscope produced by FEl company. The Raman spectra were collected via an inVia-Reflex testing system manufactured by RENISHAW company, with the excitation wavelength of $785 \mathrm{~nm}$.

\section{Results And Discussion}

\section{Synthesis and characterization of nano $\mathrm{Ta}_{4} \mathrm{HfC}_{5}$ powder}

Prior to mechanical alloying, the powder mixture of the TaC-HfC shows sharp diffraction peaks (Fig. 1). After $0.5 \mathrm{~h}$ of milling, the intensities of the corresponding diffraction peaks are reduced and the full width at half maximum (FWHM) becomes wider. This should be argued to the grain refinement of TaC and HfC. As the milling time further raises to $1 \sim 5 \mathrm{~h}$, these crystalline peaks decrease gradually and finally disappear after $10 \mathrm{~h}$ of milling. At this stage, the decrease of nanocrystalline peak intensities and the increase of FWHM are mainly due to the gradual solid solution of $\mathrm{TaC}$ and $\mathrm{HfC}$. Interestingly, the singlephase $\mathrm{Ta}_{4} \mathrm{HfC}_{5}$ solid solution is obtained after mechanical alloying for $10 \mathrm{~h}$. Further prolonging the milling time to $20 \sim 30 \mathrm{~h}$, the diffraction peaks of the as-prepared $\mathrm{Ta}_{4} \mathrm{HfC}_{5}$ gradually decrease, implying the grain refinement of $\mathrm{Ta}_{4} \mathrm{HfC}_{5}$ (Fig. 2).

After mechanical alloying, the diffraction peaks of the as-prepared $\mathrm{Ta}_{4} \mathrm{HfC}_{5}$ shifting to the small angle direction must result from the radius difference between $\mathrm{Hf}$ and $\mathrm{Ta}$, which can be depicted by the Vegard's law:

$$
a=a_{1} c_{1}+a_{2} c_{2}
$$

Where $a_{1} a_{1}$ and $a_{2}$ represent the lattice constant of the new forming solid solution, and the two starting components, respectively. The $c_{1}$ and $c_{2}$ represent the concentration of the two starting components, respectively ${ }^{[34-36]}$. The radius of the $\mathrm{Hf}$ is bigger than that of Ta. Thus, the short-range diffusion of $\mathrm{Hf}$ atoms into the interstitial sites of Ta can lead to the expansion of TaC lattice. 
TEM analyses confirm the raw materials of $\mathrm{TaC}$ and $\mathrm{HfC}$ powders both have relatively large grain size [Fig. 3(a) and (b)]. Besides, the corresponding SAED pattern displays some diffraction spots and rings of $\mathrm{HfC}$ and TaC [Fig. 3(c)]. After ball milling for only $0.5 \mathrm{~h}$, the grain size of $\mathrm{TaC}$ and $\mathrm{HfC}$ decreases obviously and some diffraction spots of $\mathrm{TaC}$ and $\mathrm{HfC}$ have disappeared [Fig. 3(d-f)]. Notably, at this milling time, mechanical alloying has induced many structural defects in both $\mathrm{TaC}$ and $\mathrm{HfC}$, which can provide convenient channel for $\mathrm{Hf}$ atoms diffusing inward. With the progressing milling of $30 \mathrm{~h}$, only pure $\mathrm{Ta}_{4} \mathrm{HfC}_{5}$ nanocrystals are obtained without any trace of $\mathrm{HfC}$ or below the limits of detection [Fig. $3(\mathrm{~g}-\mathrm{i})$ ]. For pure TaC ball-milled for $30 \mathrm{~h}$ [Fig. 3(j-1)], SAED pattern with bright-spots and narrow-rings verifies the well-defined crystalline phase of TaC.

The SEM surface morphologies in Fig. 4(a) further ensure that the raw materials of TaC-HfC powder mixture have larger particle size. Nevertheless, after mechanical alloying for $0.5 \mathrm{~h}$, the particle size of the powder mixture decreases obviously, which is mainly composed of nano-particles [Fig. 4(b)]. With the progress of mechanical alloying (1.5-30 h), these particles are continuously deformed, crushed and cold sintered; however, the morphologies of the resulting particles are almost unchanged. The EDS maps in Fig. 4(f)-(i) confirm that the $\mathrm{Ta}, \mathrm{Hf}$ and $\mathrm{C}$ atoms distribute uniformly after $30 \mathrm{~h}$ of milling, suggesting a good solid solubility of $\mathrm{Hf}$ into TaC.

Figure 5 shows the XRD patterns of the in situ $\mathrm{SiBCN}-\mathrm{Ta}_{4} \mathrm{HfC}_{5}$ amorphous-nanocrystalline composite powder with different $\mathrm{Ta}_{4} \mathrm{HfC}_{5}$ content. After $20 \mathrm{~h}$ of mechanical alloying, the lattice structure of c-Si, $\mathrm{h}$ $\mathrm{BN}$ and graphite was destroyed to form amorphous SiBCN. Besides, the broad diffraction peaks of $\mathrm{Ta}_{4} \mathrm{HfC}_{5}$ were observed, and these peak intensities gradually increase with the increase of $\mathrm{Ta}_{4} \mathrm{HfC}_{5}$ content. Confidently, the nano $\mathrm{Ta}_{4} \mathrm{HfC}_{5}$ does not react with other components of SiBCN and still presents the form of nanocrystals $\sim 3-5 \mathrm{~nm}$ in the amorphous matrix after mechanical alloying (Fig. 6).

The formation mechanisms of the mechanical alloying derived nano $\mathrm{Ta}_{4} \mathrm{HfC}_{5}$ are elaborated in Fig. 7 . During the mechanical alloying process, the sample particles are continuously deformed, crushed and cold sintered under mechanical impact conditions, which led to grain refinement and microstrain occurring in the crystal grains. The dislocation density can be represented by the following equation [37].

$$
\rho_{\mathrm{D}}=2 \sqrt{3} \frac{\left(\varepsilon^{2}\right)^{\frac{1}{2}}}{D b}
$$

Where $\varepsilon$ is the microstrain, $D$ is the grain size, and $b$ is the Burgers vector. According to formula (2), larger microstrain and smaller grain size lead to higher dislocation density in the crystal. Besides, the decrease in grain size results in an increase in surface area per unit volume. Higher surface energy provides a driving force for diffusion, while more defects provide channels for atom diffusion. Therefore, a uniform solid solution of $\mathrm{Ta}_{4} \mathrm{HfC}_{5}$ was formed. 


\section{Microstructural evolution and mechanical properties of as- sintered $\mathrm{SiBCN}-\mathrm{Ta}_{4} \mathrm{HfC}_{5}$ composite ceramics}

After reactive hot-pressing sintering, $\mathrm{SiBCN}-\mathrm{Ta}_{4} \mathrm{HfC}_{5}$ composite ceramics mainly consist of $\mathrm{BN}(\mathrm{C})$, $\beta$-SiC, a-SiC and $\mathrm{Ta}_{4} \mathrm{HfC}_{5}$ (Fig. 8). Obviously, the intensity of the diffraction peaks of the $\mathrm{Ta}_{4} \mathrm{HfC}_{5}$ is positively correlated with the content of $\mathrm{Ta}_{4} \mathrm{HfC}_{5}$. Interestingly, with the increase of $\mathrm{Ta}_{4} \mathrm{HfC}_{5}$ content, the diffraction peaks of a-SiC decrease while the diffraction peaks of $\beta$-SiC increase. These means that the in situ $\mathrm{Ta}_{4} \mathrm{HfC}_{5}$ affects the $\beta \rightarrow \mathrm{a}$ transition of SiC.

Figure 9 exhibits the Raman spectra of the as-sintered $\mathrm{SiBCN}-\mathrm{Ta}_{4} \mathrm{HfC}_{5}$ composite ceramics with various $\mathrm{Ta}_{4} \mathrm{HfC}_{5}$ content. Two Raman peaks in a range of $1250-1750 \mathrm{~cm}^{-1}$ are gradually enhanced with the increase content of the in situ $\mathrm{Ta}_{4} \mathrm{HfC}_{5}$. The emergence of Raman peak at $1374 \mathrm{~cm}^{-1}$ results from the Dside peak edge of graphite and the scattering peak of $h-B N{ }^{[5]}$. However, the generation of Raman peak at $1588 \mathrm{~cm}^{-1}$ should be assigned to the G-side peak of graphite ${ }^{[38]}$.

After hot-pressing sintering, amorphous $\mathrm{SiBCN}$ has crystallized to product turbostratic $\mathrm{BN}(\mathrm{C})$ and nano $\mathrm{SiC}$ (Fig. 10). For pure SiBCN, BN(C) phase is distributed at the grain boundaries of SiC grains. Besides, the Si elements are mainly distributed in $\mathrm{SiC}$ grains, while $\mathrm{B}, \mathrm{C}$ and $\mathrm{N}$ elements are distributed in the form of $\mathrm{BN}(\mathrm{C})$ phase at $\mathrm{SiC}$ grain boundaries. With $2.5 \mathrm{wt} \% \mathrm{Ta}_{4} \mathrm{HfC}_{5}$ addition, most of the $\mathrm{Ta}_{4} \mathrm{HfC}_{5} \sim 10 \mathrm{~nm}$ are distributed in $\mathrm{BN}(\mathrm{C})$ phase in the form of nanocrystals (Fig. 11). The $\mathrm{Ta}_{4} \mathrm{HfC}_{5}$ grains are thereby separated by $\mathrm{BN}(\mathrm{C})$. This structure is beneficial to the grain refinement of $\mathrm{Ta}_{4} \mathrm{HfC}_{5}$ and constrains shortrange diffusion of the atoms. The EDS maps of the selective region in $\mathrm{Ta}_{4} \mathrm{HfC}_{5}-\mathrm{BN}(\mathrm{C})$ clearly show that the $\mathrm{Ta}$, $\mathrm{Hf}$ and some $\mathrm{C}$ elements are distributed in $\mathrm{Ta}_{4} \mathrm{HfC}_{5}$ phase, while the rest of $\mathrm{C}$ elements are distributed in $\mathrm{BN}(\mathrm{C})$ phase (Fig. 12). With $10 \mathrm{wt} \% \mathrm{Ta}_{4} \mathrm{HfC}_{5}$ addition, a part of nano $\mathrm{Ta}_{4} \mathrm{HfC}_{5} \sim 10 \mathrm{~nm}$ is still uniformly distributed in $\mathrm{BN}(\mathrm{C})$, while other nano $\mathrm{Ta}_{4} \mathrm{HfC}_{5}>10 \mathrm{~nm}$ is randomly distributed in the ceramic matrix (Fig. 13). The microstructural evolution diagram of the $\mathrm{SiBCN}-\mathrm{Ta}_{4} \mathrm{HfC}_{5}$ composite ceramics with different $\mathrm{Ta}_{4} \mathrm{HfC}_{5}$ content is displayed in Fig. 14 .

The flexural strength and fracture toughness of the as-sintered $\mathrm{SiBCN}-\mathrm{Ta}_{4} \mathrm{HfC}_{5}$ composite ceramics are shown in Fig. 15. Apparently, the introduction of $\mathrm{Ta}_{4} \mathrm{HfC}_{5}$ nanocrystals has effectively improved the flexural strength and fracture toughness of the SiBCN ceramics. For pure SiBCN ceramics, they only show flexural strength of $156.1 \mathrm{MPa}$ and fracture toughness of $1.82 \mathrm{MPa} \cdot \mathrm{m}^{1 / 2}$, respectively. With $10 \mathrm{wt} \%$ $\mathrm{Ta}_{4} \mathrm{HfC}_{5}$ addition, the composite ceramics possess optimized flexural strength reaching to $344.1 \mathrm{MPa}$, while the composite ceramics with $5 \mathrm{wt} \% \mathrm{Ta}_{4} \mathrm{HfC}_{5}$ obtain fracture toughness of $4.52 \mathrm{MPa} \cdot \mathrm{m}^{1 / 2}$.

\section{Conclusion}

In this study, $\mathrm{SiBCN}-\mathrm{Ta}_{4} \mathrm{HfC}_{5}$ composite ceramics were prepared by two-step mechanical alloying combined with reactive hot-pressing sintering. After the above analysis, the following conclusions can be 
drawn:

(1) In the initial step of mechanical alloying of $30 \mathrm{~h}, \mathrm{TaC}-\mathrm{HfC}$ powder mixture are crushed, cold sintered and interdiffused, and finally form $\mathrm{Ta}_{4} \mathrm{HfC}_{5}$ nanocrystalline. After the second step of milling for $20 \mathrm{~h}$, a hybrid structure of amorphous $\mathrm{SiBCN}$ and nano $\mathrm{Ta}_{4} \mathrm{HfC}_{5}$ can be obtained. The lattice structures of $\mathrm{C}-\mathrm{Si}$, h$\mathrm{BN}$ and graphite were destroyed to form amorphous structures. However, $\mathrm{Ta}_{4} \mathrm{HfC}_{5}$ is uniformly distributed in amorphous powder in the form of nanocrystals.

(2) After reactive hot-pressing sintering, $\mathrm{SiBCN}-\mathrm{Ta}_{4} \mathrm{HfC}_{5}$ composite ceramics mainly contain $\mathrm{Ta}_{4} \mathrm{HfC}_{5}$, $\mathrm{BN}(\mathrm{C}), \beta-\mathrm{SiC}$ and $\mathrm{a}-\mathrm{SiC}$. The $\mathrm{Ta}_{4} \mathrm{HfC}_{5}$ still exists in the form of nanocrystalline and does not react with the $\mathrm{SiBCN}$ matrix composition. With only $2.5 \mathrm{wt} \% \mathrm{Ta}_{4} \mathrm{HfC}_{5}$ addition, nano $\mathrm{Ta}_{4} \mathrm{HfC}_{5}$ is preferentially distributed in $\mathrm{BN}(\mathrm{C})$ phase; however, it tends to both distribute in $\mathrm{BN}(\mathrm{C})$ phase and ceramic matrix when $10 \mathrm{wt} \%$ $\mathrm{Ta}_{4} \mathrm{HfC}_{5}$ is adopted.

(3) The introduction of the $\mathrm{Ta}_{4} \mathrm{HfC}_{5}$ nanocrystals can effectively improve the flexural strength and fracture toughness of SiBCN ceramics due to the grain refinement and uniform distribution of nano $\mathrm{Ta}_{4} \mathrm{HfC}_{5}$. SiBCN ceramics with $10 \mathrm{wt} \% \mathrm{Ta}_{4} \mathrm{HfC}_{5}$ present optimized flexural strength of $344.1 \mathrm{MPa}$, while composite ceramics with $5 \mathrm{wt} \% \mathrm{Ta}_{4} \mathrm{HfC}_{5}$ obtain fracture toughness of $4.52 \mathrm{MPa} \cdot \mathrm{m}^{1 / 2}$.

\section{Declarations}

\section{Acknowledgements}

Financial support from the National Natural Science Foundation of China under grant numbers of $51621091,51472059,51225203$ and 51272300 is much appreciated. This work is also funded by National Key Research and Development Program (Grant No. 2017YFB0310400), Postdoctoral Innovative Talents Support Program with Grant No BX20190095 and China Postdoctoral Science Foundation under grant numbers of $2019 \mathrm{M} 660072$.

\section{References}

[1] Z. Zhang, X. Duan, B. Qiu, Z. Yang, D. Cai, P. He, D.Jia, Y. Zhou, Preparation and anisotropic properties of textured structural ceramics: A review, Journal of Advanced Ceramics 8 (2019) 289-332.

[2] R. Riedle, A. Kienzle, W. Dressler, L. Ruwisch, J. Bill, F. Aldinger, A silicoboron carbonitride ceramic stable to $2000^{\circ} \mathrm{C}$, Nature 382 (1996) 796-798.

[3] R. Riedle, L.M. Ruswisch, L. An, R. Raj, Amorphous silicoboron carbonitride ceramic with very high viscosity at temperatures above $1500^{\circ} \mathrm{C}$, Journal of the American Ceramic Society 81 (2005) 3341-3344.

[4] N.V.R. Kumar, S. Prinz, C. Ye, A. Zimmermann, F. Aldinger, F. Berger, K. Müller, Crystallization and creep behavior of Si-B-C-N ceramics, Acta Materialia 53 (2005) 4567-4578. 
[5] N. Liao, D. Jia, Z. Yang, Y. Zhou, Y. Li, Enhanced thermal shock and oxidation resistance of $\mathrm{Si}_{2} \mathrm{BC}_{3} \mathrm{~N}$ ceramics through MWCNTs incorporation. Journal of Advanced Ceramics 7 (2018) 276-288.

[6] N. Liao, D. Jia, Z. Yang, Y. Zhou, Enhanced mechanical properties and thermal shock resistance of $\mathrm{Si}_{2} \mathrm{BC}_{3} \mathrm{~N}$ ceramics with SiC coated MWCNTs. Journal of Advanced Ceramics 8 (2019) 121-132.

[7] J. Wang, Z. Yang, X. Duan, D. Jia, Y. Zhou, Microstructure and mechanical properties of $\mathrm{SiC}_{\mathrm{f}} / \mathrm{SiBCN}$ ceramic matrix composites. Journal of Advanced Ceramics 4 (2015) 31-38.

[8] T.G. Babu, R. Devasia, Simple and low-cost synthetic route for SiBCN ceramic powder from a boron modified cyclotrisilazane, Journal of the American Ceramic Society 102 (2019) 476-489.

[9] C. Song, X. Liu, F. Ye, Y. Liu, L. Cheng, Mechanical and dielectric properties of $\mathrm{SiC}_{f} / \mathrm{BN} / \mathrm{SiBCN}$ composites via different synthesis technologies, Journal of the European Ceramic Society 39 (2019) 4417-4423.

[10] D. Jia, B. Liang, Z. Yang, Z. Yu, Metastable Si-B-C-N ceramics and their matrix composites developed by inorganic route based on mechanical alloying: Fabrication, microstructures, properties and their relevant basic scientific issues, Progress in Materials Science 98 (2018) 1-67.

[11] D. Li, Q. Li, J. Yuan, Z. Yang, D. Jia, D. Cai, S. Wang, Y. Zhou, D. Yu, Y. Tian, Effects of high pressure on the low-temperature sintering of dense amorphous SiBCN monoliths, Journal of the European Ceramic Society 38 (2018) 3777-3786.

[12] P. Zhang, D. Jia, Z. Yang, X. Duan, Y. Zhou, Progress of a novel non-oxide Si-B-C-N ceramic and its matrix composites, Journal of Advanced Ceramics 1 (2012) 157-178.

[13] J. Wang, X. Duan, Z. Yang, D. Jia, Y. Zhou, Ablation mechanism and properties of $\mathrm{SiC}_{f} / \mathrm{SiBCN}$ ceramic composites under an oxyacetylene torch environment, Corrosion Science 82 (2014) 101-107.

[14] D. Li, Z. Yang, D. Jia, X. Duan, P. He, Y. Zhou, Ablation behavior of graphene reinforced SiBCN ceramics in an oxyacetylene combustion flame, Corrosion Science 100 (2015) 85-100.

[15] N. Liao, D. Jia, Z.H. Yang, B. Niu, Y. Zhou, Y. Li, Enhanced mechanical properties, thermal shock resistance and ablation resistance of $\mathrm{Si}_{2} \mathrm{BC}_{3} \mathrm{~N}$ ceramics with nano $\mathrm{ZrB}_{2}$ addition, Journal of the European Ceramic Society 39 (2019) 846-859.

[16] B. Feng, Y. Zhang, B. Li, Medium-temperature sintering efficiency of $\mathrm{ZrB}_{2}$ ceramics using polymerderived SiBCN as a sintering aid, Journal of the European Ceramic Society 102 (2019) 855-866.

[17] B. Wang, Z. Yang, D. Li, D. Cai, B. Niu, J. Guan, D. Jia, Y. Zhou, Effects of TaC addition on microstructure and mechanical properties of SiBCN composite ceramics, Ceramics International. 45 (2019) 22138-22147.. 
[18] M. Sun, R. Fu, J. Chen, Fabrication and microstructures of functional gradient SiBCN-Nb composite by hot pressing, Materials Characterization 114 (2019) 115-121.

[19] B. Feng, Y. Zhang, B. Li, S. Hu, Medium-temperature sintering efficiency of $\mathrm{ZrB}_{2}$ ceramics using polymer-derived SiBCN as a sintering aid, Journal of the American Ceramic Society. 102 (2019) 855-866.

[20] S. Wang, Y. Zhang, S. Yong, X. Yao, Y. Ming, Synthesis and characteristic of SiBCN/HfN ceramics with high temperature oxidation resistance, Journal of Alloys and Compounds. 685 (2016) 828-835.

[21] B. Liang, Z. Yang, D. Jia, S. Guo, Q. Zhu, X. Liao, Y. Miao, Q. Zhang, Y. Zhou, Densification, microstructural evolution and mechanical properties of Si-B-C-N monoliths with $\mathrm{LaB}_{6}$ addition, Journal of Alloys and Compounds 696 (2017) 1090-1095.

[22] B. Liang, Z. Yang, Y. Miao, Q. Zhu, X. Liao, Q. Li, Z. Tian, D. Jia, Y. Zhou, Si-B-C-N monoliths with LaB $6^{-}$ induced well-developed BN(C) flakes, Materials Letters 187 (2017) 36-39.

[23] B. Liang, Z. Yang, Y. Miao, Q. Li, Q. Zhu, X. Liao, D. Jia, Y. Zhou, Microstructural evolution, mechanical and thermal properties of $\mathrm{LaB}_{6}$ embedded in Si-B-C-N prepared by spark plasma sintering, Ceramics International. 43 (2017) 4814-4820.

[24] Y. Miao, Z. Yang, B. Liang, Q. Li, Q. Chen, D. Jia, Y.B. Cheng, Y. Zhou, A novel in situ synthesis of SiBCN-Zr composites prepared by a sol-gel process and spark plasma sintering, Dalton Transactions. 45 (2016) 12739-12744.

[25] Y. Miao, Z. Yang, J. Rao, X. Duan, P. He, D. Jia, Y. Cheng, Y. Zhou, Influence of sol-gel derived ZrB 2 additions on microstructure and mechanical properties of SiBCN composites, Ceramics International. 43 (2017) 4372-4378.

[26] Y. Miao, Z. Yang, Q. Zhu, B. Liang, L. Quan, T. Zhuo, D. Jia, Y.B. Cheng, Z. Yu, Thermal ablation behavior of SiBCN-Zr composites prepared by reactive spark plasma sintering, Ceramics International. 43 (2017) 7978-7983.

[27] Agte C, Alterthum H, Investigations of the High-Melting Carbide Systems Connected with Problem of the Carbon Melting, Z. Techn. Phys. 11 (1930) 182.

[28] Andrievskii R A, Strel'Nikova N S, Poltoratskii N I, Melting point in systems ZrC-HfC, TaC-ZrC, TaC-HfC, Soviet Powder Metallurgy \& Metal Ceramics. 6 (1967) 65-67.

[29] E. P. Simonenko, N. A. Ignatov, N. P. Simonenko, Yu. S. Ezhov, V. G. Sevastyanov, N. T. Kuznetsov, Zirconium Carbide $\mathrm{Ta}_{4} \mathrm{ZrC}_{5}$ and Tantalum-Hafnium Carbide $\mathrm{Ta}_{4} \mathrm{HfC}_{5}$ via Sol-Gel Technology, Synthesis and Properties of Inorganic Compounds. 56 (2011) 1763-1769. 
[30] Y. Lu, Y. Sun, T. Zhang, F. Chen, L. Ye, T. Zhao, Polymer-derived $\mathrm{Ta}_{4} \mathrm{HfC}_{5}$ nanoscale ultrahightemperature ceramics: Synthesis, microstructure and properties, Journal of the European Ceramic Society. 39 (2019) 205-211.

[31] Osama Gaballa, B.A. Cook, A.M. Russell, Reduced-temperature processing and consolidation of ultrarefractory $\mathrm{Ta}_{4} \mathrm{HfC}_{5}$, Int. Journal of Refractory Metals and Hard Materials. 41 (2013) 293-299

[32] N. Liao, D. Jia, Z. Yang, Y. Zhou, Y. Li, X. Jia, Strengthening and toughening effects of MWCNTs on $\mathrm{Si}_{2} \mathrm{BC}_{3} \mathrm{~N}$ ceramics sintered by SPS technique, Materials Science and Engineering A. 710 (2018) 142-150.

[33] N. Liao, D. Jia, Z. Yang, Z. Yu, Y. Li, Mechanical properties and thermal shock resistance of $\mathrm{Si}_{2} \mathrm{BC}_{3} \mathrm{~N}$ ceramics with ternary $\mathrm{Al}_{4} \mathrm{SiC}_{4}$ additive, Ceramics International. 44 (2018) 9009-9017.

[34] H. Chen, B. Tang, C. Zhong, Y. Yuan, Y. Tan, S. Zhang, The dielectric constant and quality factor calculation of the microwave dielectric ceramic solid solutions, Ceramics International. 43(2017) 73837386.

[35] Q. Hang, Z. Xing, X. Zhu, M. Yu, Y. Song, J. Zhu, Z. Liu, Dielectric properties and related ferroelectric domain configurations in multiferroic $\mathrm{BiFeO}_{3}-\mathrm{BaTiO}_{3}$ solid solutions, Ceramics International. 38 (2012) S411-S414.

[36] E. Antolini, $\mathrm{Li}_{2} \mathrm{O}$ evaporation from $\mathrm{Li}_{x} \mathrm{Co}_{1-x} \mathrm{O}$ solid solutions at 1200 degrees $\mathrm{C}$, Ceramics International. 27 (2001) 675-679.

[37] K. Zaara, M. Cheinggui, V. Optasanu, M. Khitouni, Solid solution evolution during mechanical alloying in Cu-Nb-Al compounds, International Journal of Minerals Metallurgy and Materials. 26 (2019) 11291139.

[38] D. Li, Z. Yang, D. Jia, S. Wang, X. Duan, B. Liang, Q. Zhu, Y. Zhou, Structure evolution, amorphization and nucleation studies of carbon-lean to -rich SiBCN powder blends prepared by mechanical alloying, RSC Advance 6 (2016) 48255-48271.

\section{Figures}




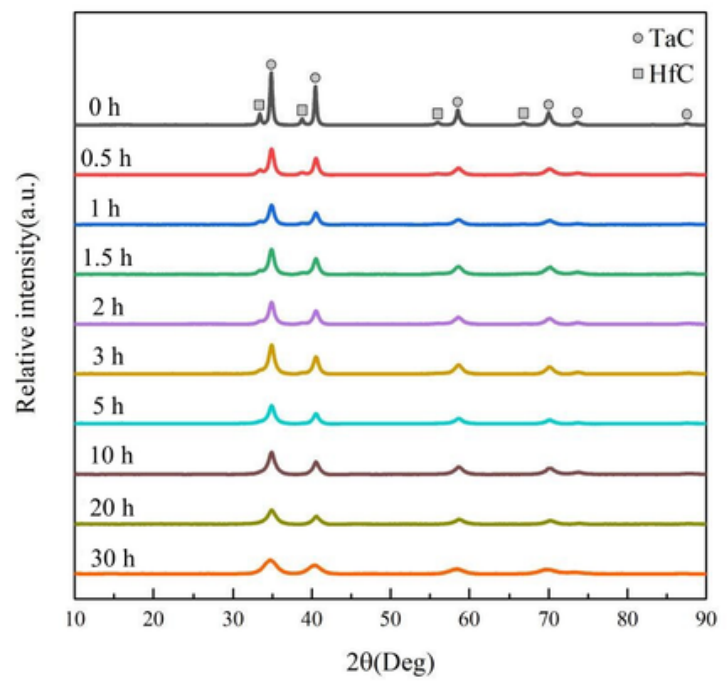

Fig. 1 The XRD patterns of the TaC-HfC powder mixture after mechanical alloying for different time.

\section{Figure 1}

The XRD patterns of the TaC-HfC powder mixture after mechanical alloying for different time. 


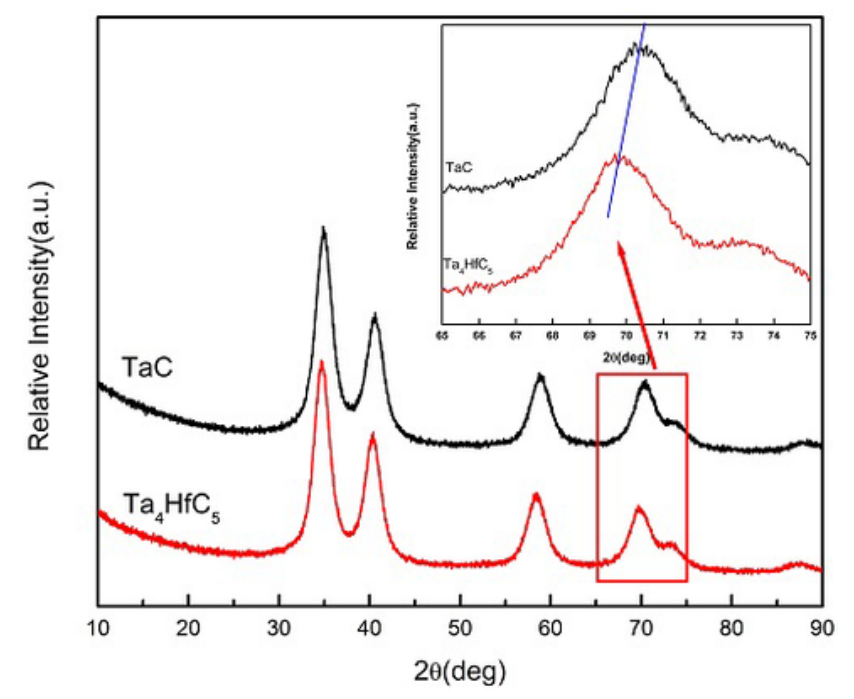

Fig. 2 The XRD patterns of pure $\mathrm{TaC}$ powder and $\mathrm{TaC}-\mathrm{HfC}$ powder mixture after mechanical alloying for $30 \mathrm{~h}$, inserted is the magnifying picture.

\section{Figure 2}

The XRD patterns of pure TaC powder and TaC-HfC powder mixture after mechanical alloying for $30 \mathrm{~h}$, inserted is the magnifying picture. 


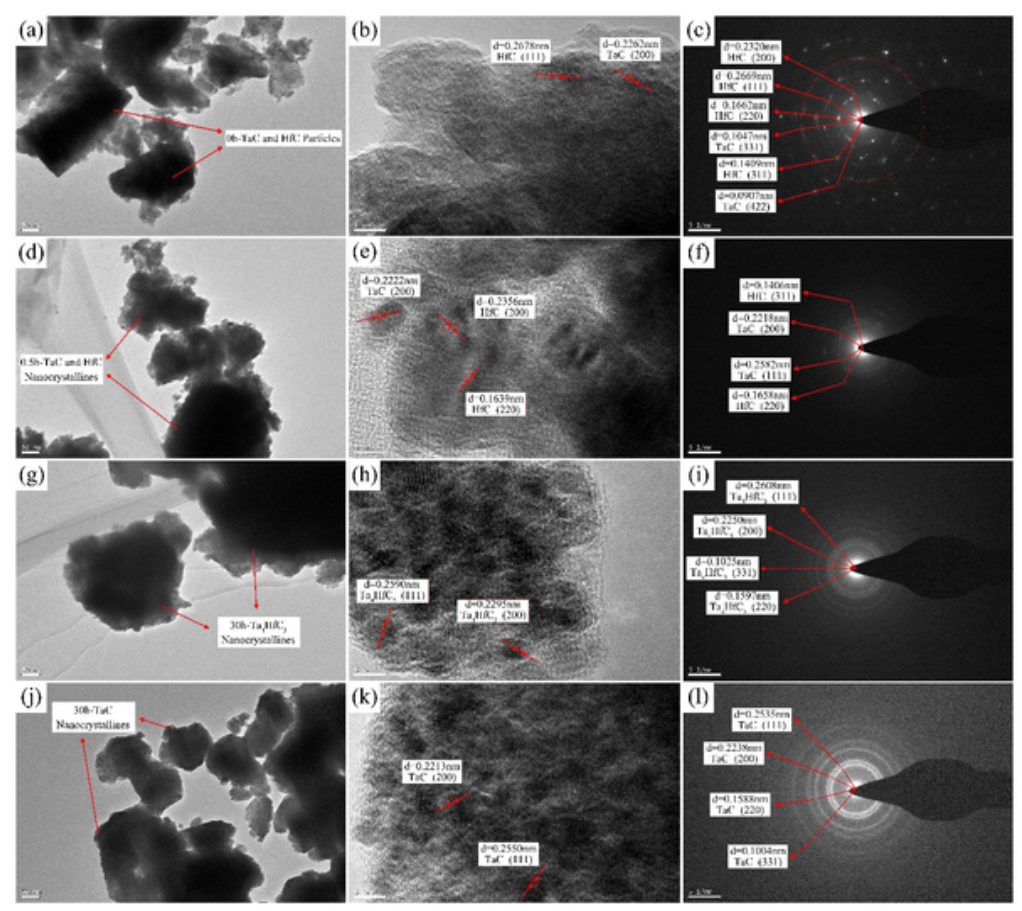

Fig. 3 The TEM, HRTEM and electron diffraction pattern (SAED) images of the pure $\mathrm{TaC}$ powder and $\mathrm{HfC}-\mathrm{TaC}$ powder mixture after mechanical alloying for different time. (a-c) HfC-TaC, 0 h; (d-f) HfC-TaC, 0.5 h; (g-i) HfC-TaC, 30 h; (j-l) pure TaC powder, $30 \mathrm{~h}$.

\section{Figure 3}

The TEM, HRTEM and electron diffraction pattern (SAED) images of the pure TaC powder and HfC-TaC powder mixture after mechanical alloying for different time. (a-c) HfC-TaC, 0 h; (d-f) HfC-TaC, 0.5 h; (g-i) $\mathrm{HfC}-\mathrm{TaC}, 30 \mathrm{~h}$; (j-l) pure TaC powder, $30 \mathrm{~h}$. 


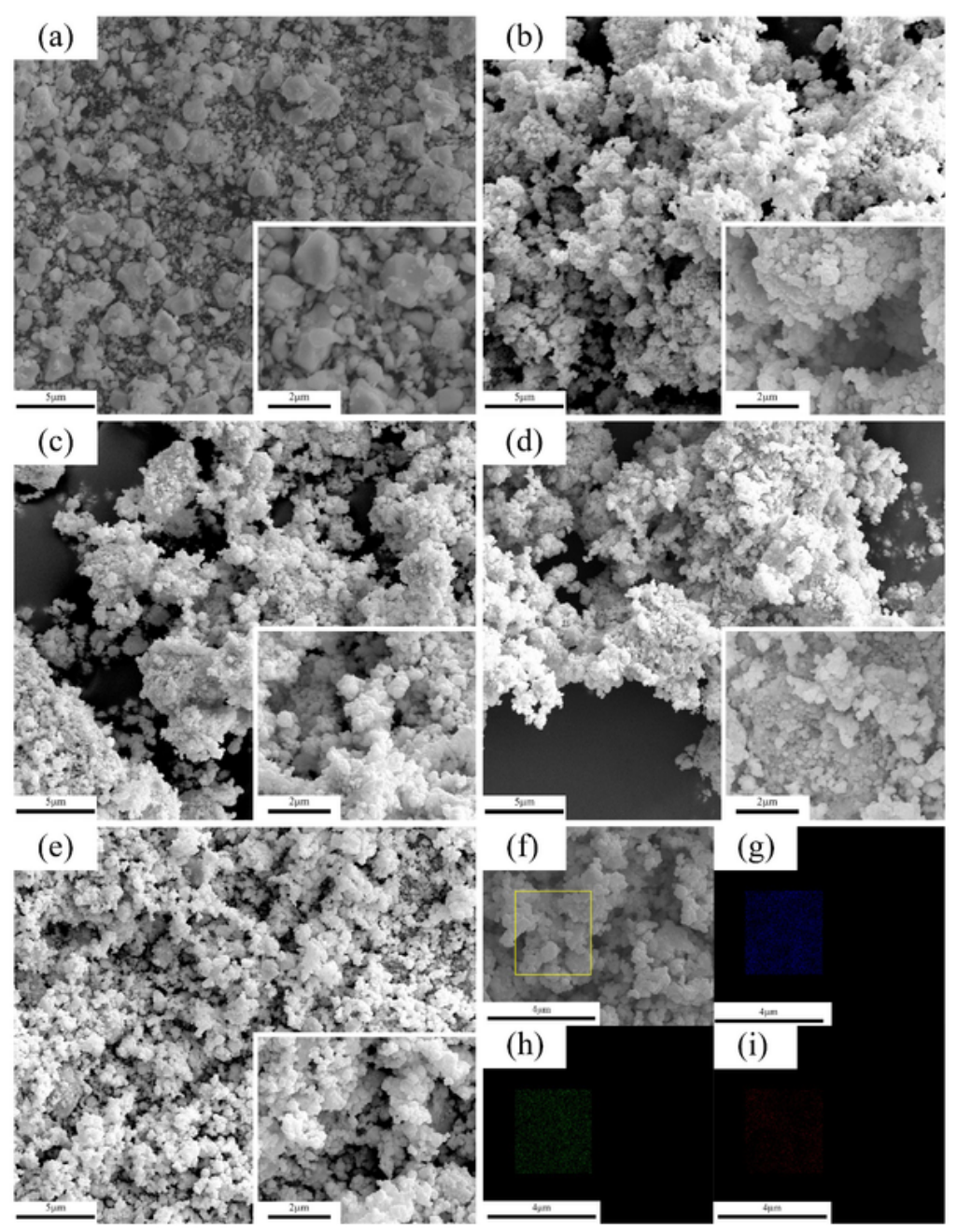

Fig.4 The SEM surface images of TaC-HfC mixed powders after mechanical alloying for different time. (a) $0 \mathrm{~h}$; (b) $0.5 \mathrm{~h}$; (c) $1.5 \mathrm{~h}$; (d) $20 \mathrm{~h}$; (e, f) $30 \mathrm{~h}$; (g-i) the corresponding element maps, the inserted are the magnifying SEM images.

\section{Figure 4}

The SEM surface images of TaC-HfC mixed powders after mechanical alloying for different time. (a) $0 \mathrm{~h}$; (b) $0.5 \mathrm{~h}$; (c) $1.5 \mathrm{~h}$; (d) $20 \mathrm{~h}$; (e, f) $30 \mathrm{~h}$; (g-i) the corresponding element maps, the inserted are the magnifying SEM images. 


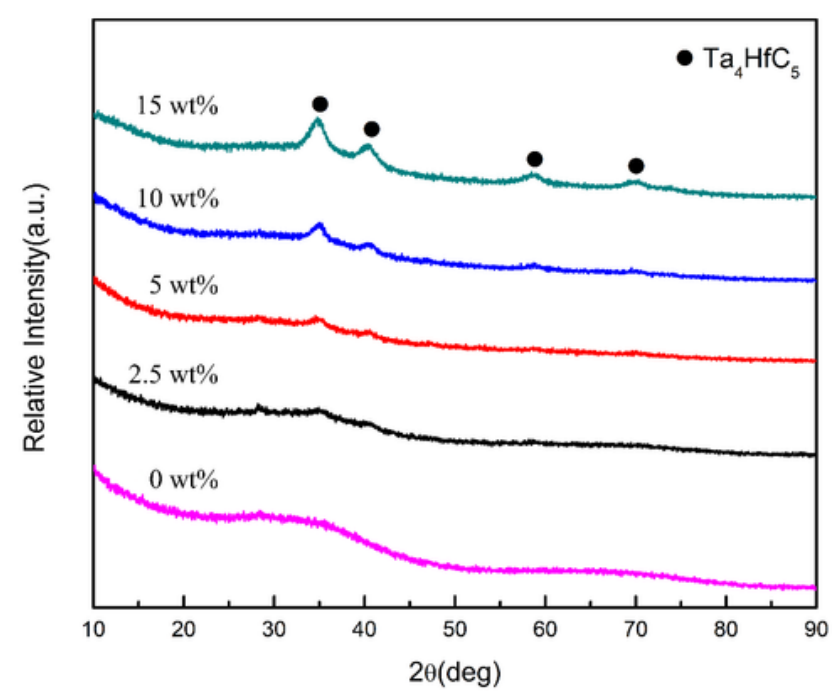

Fig. 5 The XRD patterns of in situ $\mathrm{SiBCN}_{-} \mathrm{Ta}_{4} \mathrm{HfC}_{5}$ amorphous-nanocrystalline composite powder with different $\mathrm{Ta}_{4} \mathrm{HfC}_{5}$ content.

\section{Figure 5}

The XRD patterns of in situ SiBCN-Ta4HfC5 amorphous-nanocrystalline composite powder with different Ta4HfC5 content. 

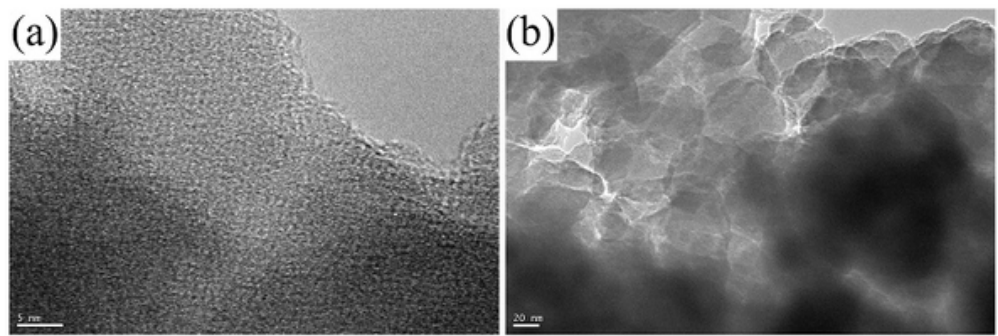

(c)

$\mathrm{d}=0.2248 \mathrm{~nm}$ $\mathrm{Ta}_{4} \mathrm{HfC}_{5}(200)$

(d)

$\mathrm{SiBCN}$
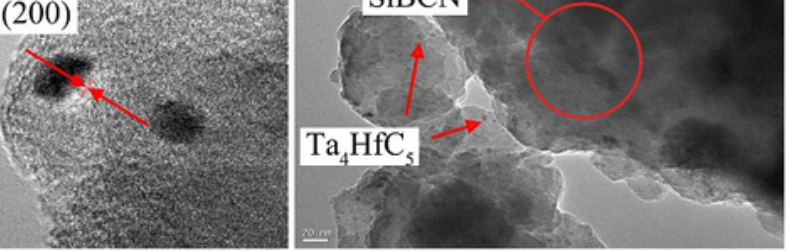

Fig. 6 The TEM and HRTEM images of the (a-b) SiBCN amorphous powder and (c-

d) $\mathrm{SiBCN}-\mathrm{Ta}_{4} \mathrm{HfC}_{5}$ amorphous-nanocrystalline composite powder.

\section{Figure 6}

The TEM and HRTEM images of the (a-b) SiBCN amorphous powder and (c-d) SiBCN-Ta4HfC5 amorphous-nanocrystalline composite powder. 


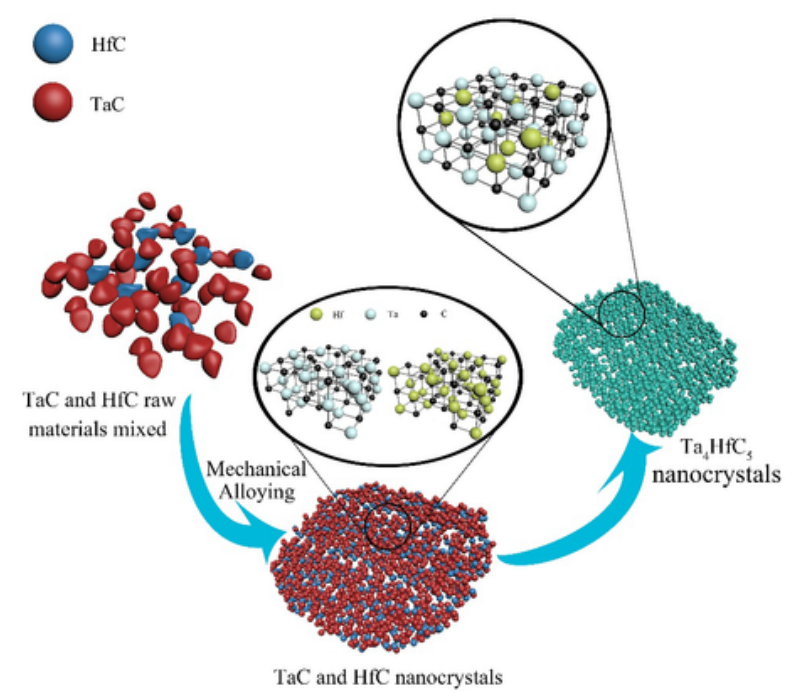

Fig. 7 The formation mechanisms of the nano $\mathrm{Ta}_{4} \mathrm{HfC}_{5}$ during mechanical alloying.

\section{Figure 7}

The formation mechanisms of the nano $\mathrm{Ta} 4 \mathrm{HfC} 5$ during mechanical alloying. 


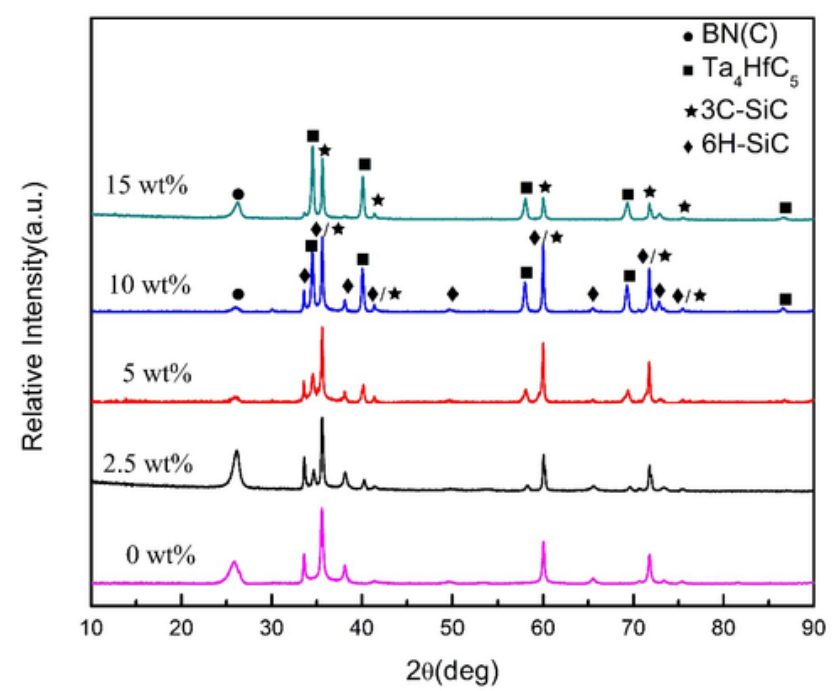

Fig. 8 The XRD patterns of the as-sintered $\mathrm{SiBCN}_{-} \mathrm{Ta}_{4} \mathrm{HfC}_{5}$ composite ceramics with different $\mathrm{Ta}_{4} \mathrm{HfC}_{5}$ content.

\section{Figure 8}

The XRD patterns of the as-sintered SiBCN-Ta4HfC5 composite ceramics with different Ta4HfC5 content. 


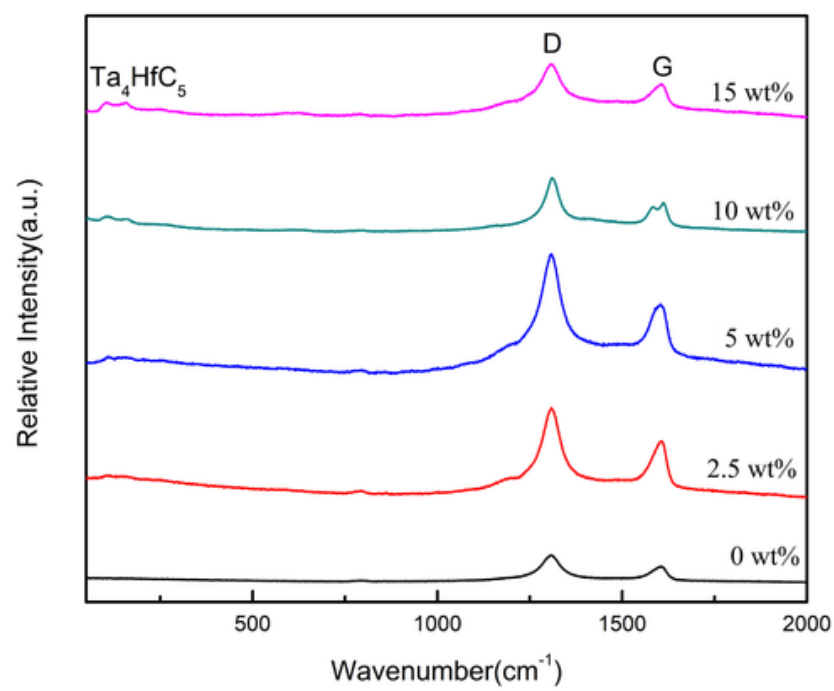

Fig. 9 The Raman spectra of the as-sintered $\mathrm{SiBCN}_{-} \mathrm{Ta}_{4} \mathrm{HfC}_{5}$ composite ceramics with different $\mathrm{Ta}_{4} \mathrm{HfC}_{5}$ content.

\section{Figure 9}

The Raman spectra of the as-sintered SiBCN-Ta4HfC5 composite ceramics with different Ta4HfC5 content. 


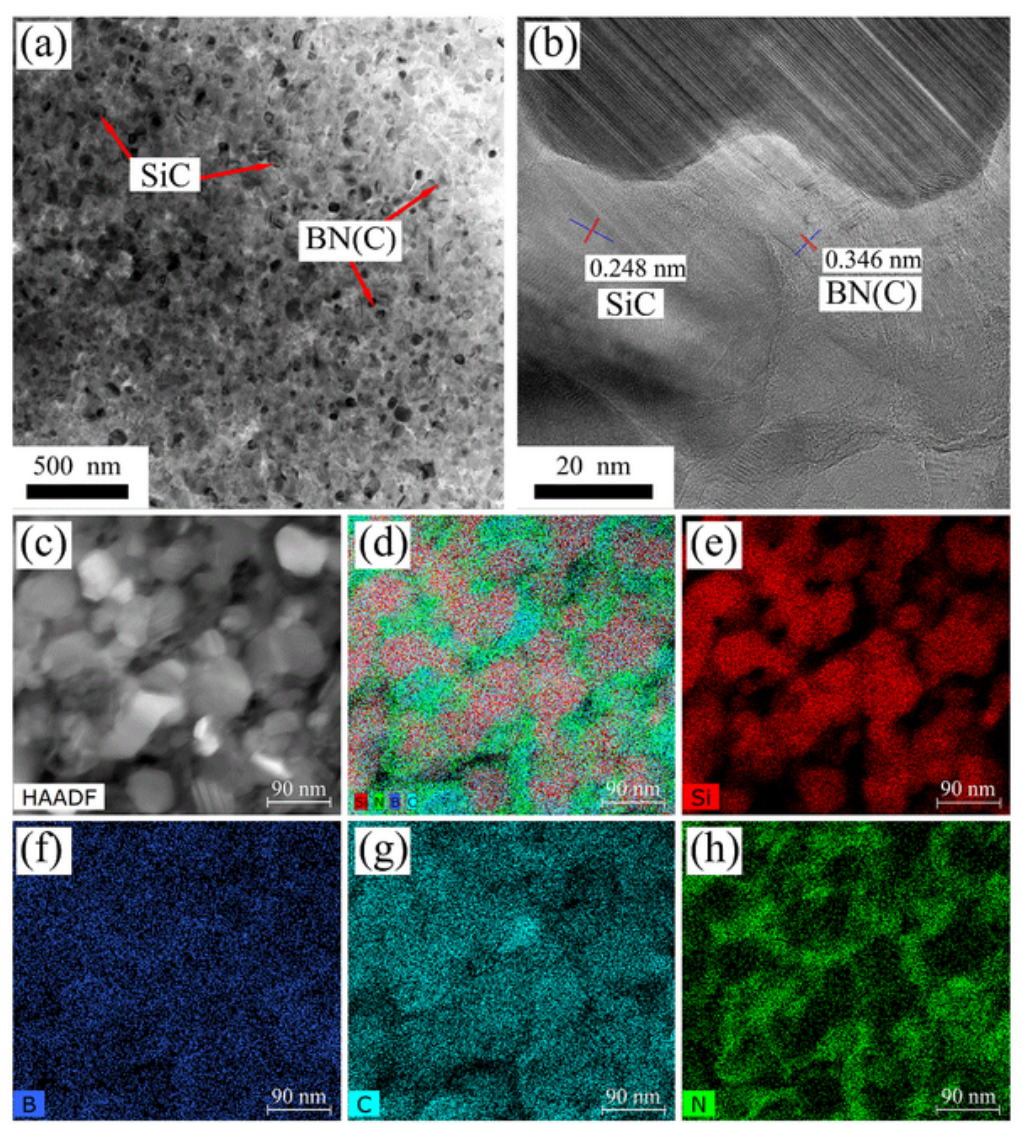

Fig. 10 The TEM and HEM images of the pure SiBCN ceramics. (a-b) Bright-field images; (c)-(j) HAADF-STEM image and corresponding EDS maps.

Figure 10

The TEM and HEM images of the pure SiBCN ceramics. (a-b) Bright-field images; (c)-(j) HAADF-STEM image and corresponding EDS maps. 

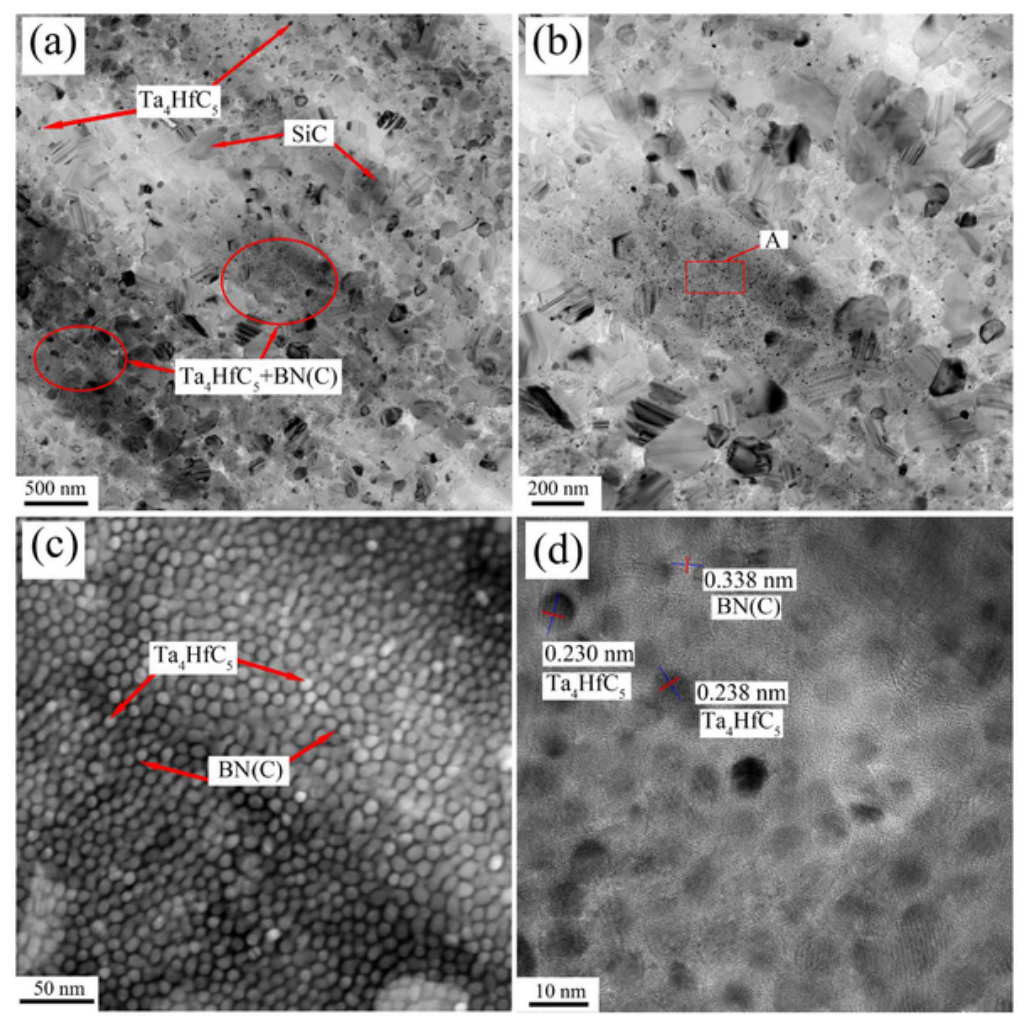

Fig. 11 The TEM and HRTEM images of the $\mathrm{SiBCN}_{-} \mathrm{Ta}_{4} \mathrm{HfC}_{5}$ composite ceramics with $2.5 \mathrm{wt} \% \mathrm{Ta}_{4} \mathrm{HfC}_{5}$. (a-b) Bright-field images; (c) Magnifying TEM image of area A; (d) HRTEM image of area A.

\section{Figure 11}

The TEM and HRTEM images of the SiBCN-Ta4HfC5 composite ceramics with $2.5 \mathrm{wt} \% \mathrm{Ta} 4 \mathrm{HfC} 5$. (a-b) Bright-field images; (c) Magnifying TEM image of area A; (d) HRTEM image of area A. 


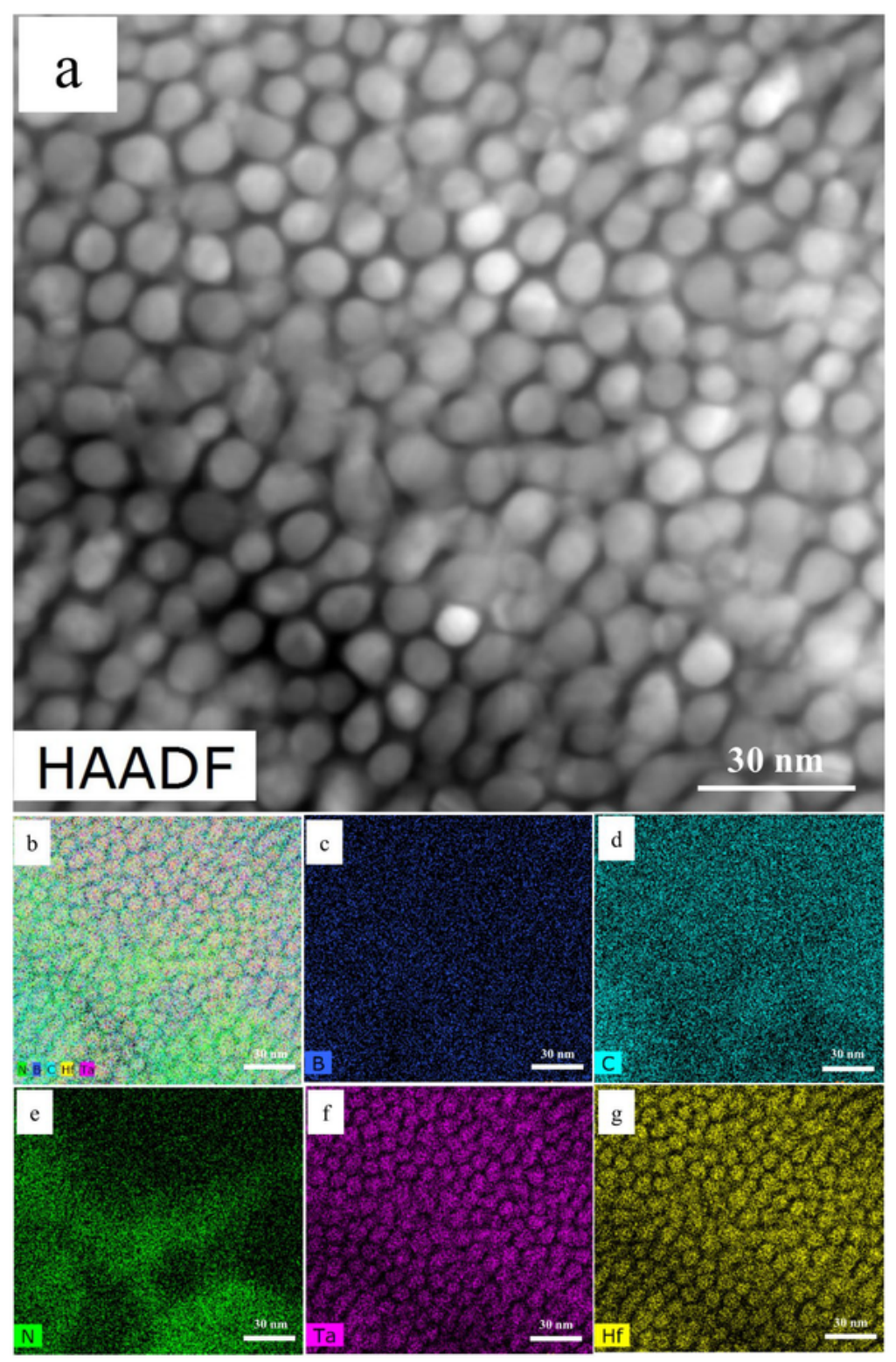

Fig.12 The selective EDS maps of $\mathrm{Ta}_{4} \mathrm{HfC}_{5}$ distributed within $\mathrm{BN}(\mathrm{C})$ region for composite ceramics with $2.5 \mathrm{wt} \% \mathrm{Ta}_{4} \mathrm{HfC}_{5}$.

Figure 12

The selective EDS maps of Ta4HfC5 distributed within $\mathrm{BN}(\mathrm{C})$ region for composite ceramics with $2.5 \mathrm{wt} \%$ Ta4HfC5. 


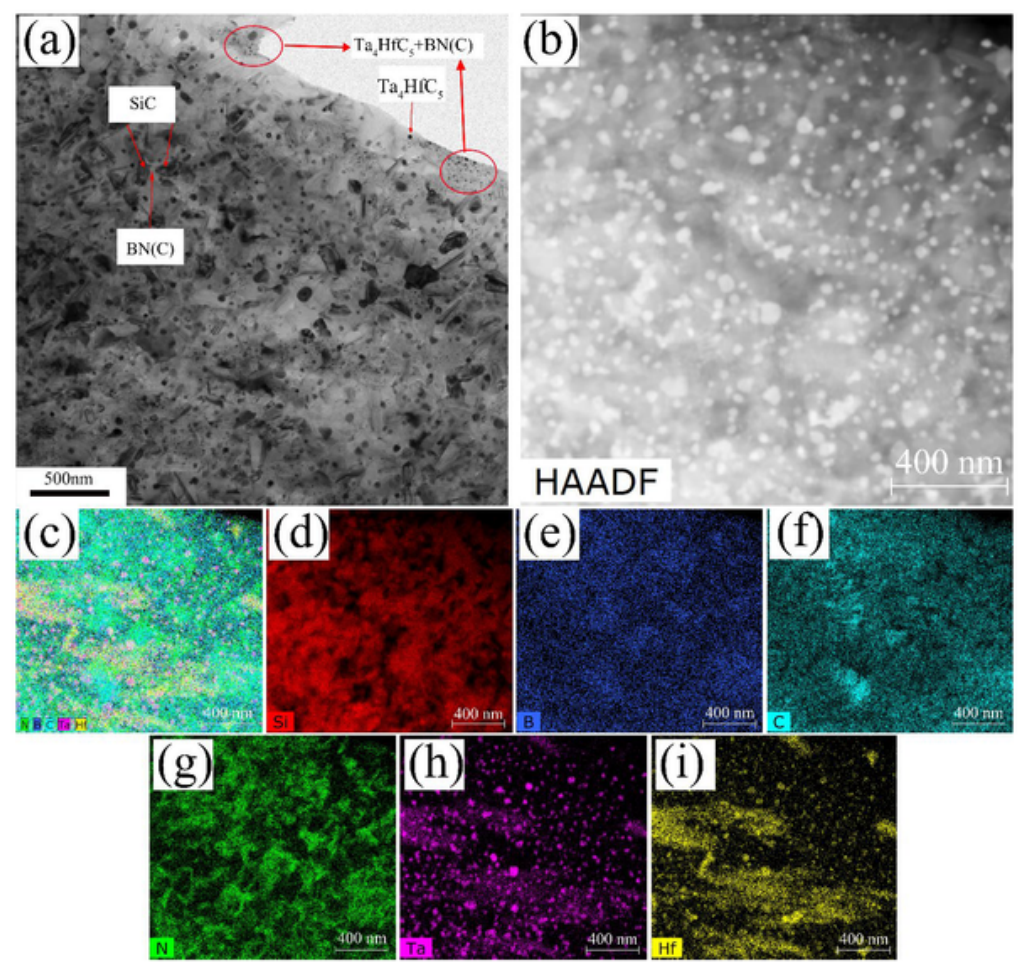

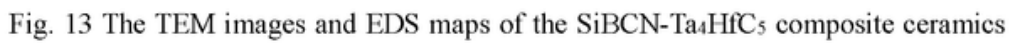
with $10 \mathrm{wt} \% \mathrm{Ta}_{4} \mathrm{HfC}_{5}$. (a) Bright-field TEM image; (b) STEM image; (d)-(j) EDS maps.

Figure 13

The TEM images and EDS maps of the SiBCN-Ta4HfC5 composite ceramics with 10 wt\% Ta4HfC5. (a) Bright-field TEM image; (b) STEM image; (d)-(j) EDS maps. 


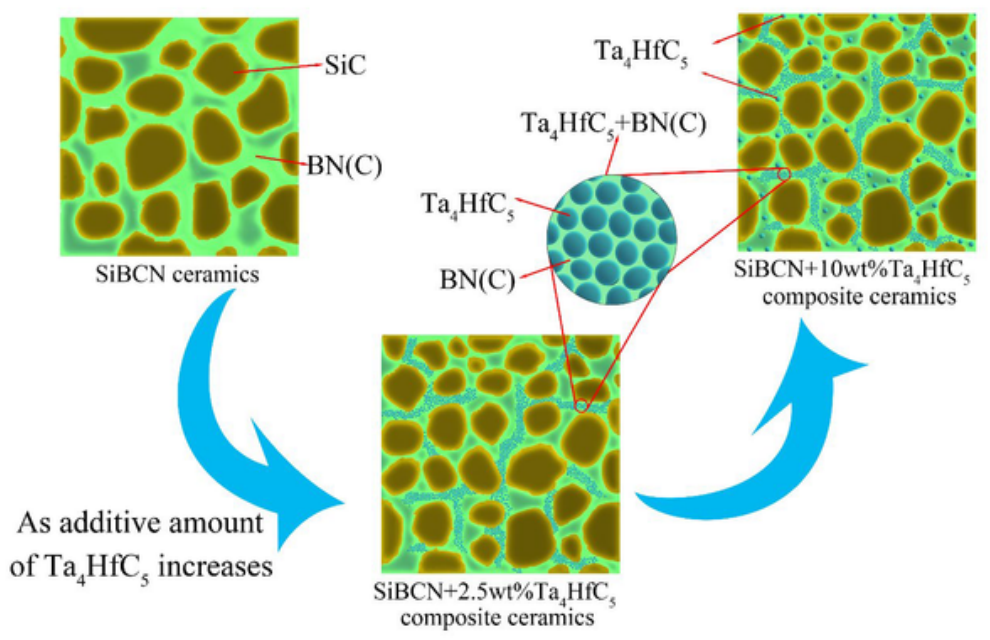

Fig.14 The schematic illustrating the microstructure evolution of $\mathrm{Ta}_{4} \mathrm{HfC}_{5}$ distribution in composite ceramics with different $\mathrm{Ta}_{4} \mathrm{HfC}_{5}$ addition.

\section{Figure 14}

The schematic illustrating the microstructure evolution of $\mathrm{Ta} 4 \mathrm{HfC} 5$ distribution in composite ceramics with different Ta4HfC5 addition. 


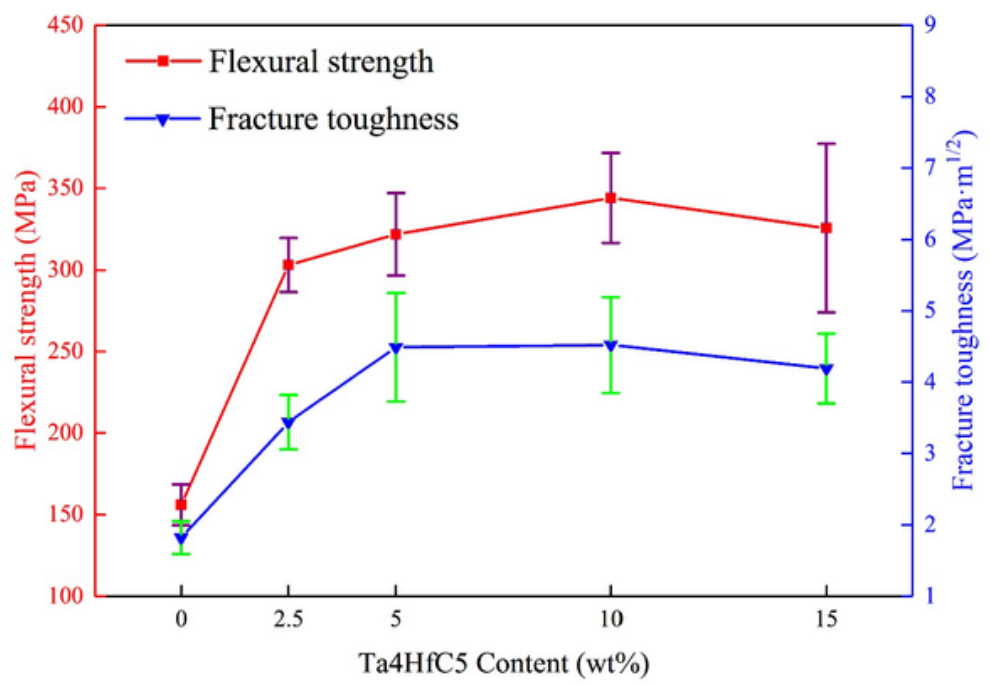

Fig. 15 The flexural strength and fracture toughness of the as-sintered SiBCN-

$\mathrm{Ta}_{4} \mathrm{HfC}_{5}$ composite ceramics with different content of $\mathrm{Ta}_{4} \mathrm{HfC}_{5}$.

\section{Figure 15}

The flexural strength and fracture toughness of the as-sintered SiBCN-Ta4HfC5 composite ceramics with different content of Ta4HfC5. 